\title{
Development and characterization of 16 polymorphic microsatellite markers for the highly invasive ascidian, Ciona savignyi
}

\author{
Ping Ni $\cdot$ Yaping Lin $\cdot$ Yiyong Chen $\cdot$ \\ Haitao Li $\cdot$ Yan Zhao $\cdot$ Aibin Zhan
}

Received: 3 September 2014/Accepted: 8 September 2014/Published online: 14 September 2014

(C) Springer Science+Business Media Dordrecht 2014

\begin{abstract}
The Pacific transparent ascidian Ciona savignyi, which is considered native to Japan and possibly northern Asia, has successfully invaded coasts of temperate regions and even Southern Hemisphere. The significantly negative effects on local biodiversity caused by invasions of this ascidian have resulted in challenges in biological conservation. In order to study its dispersal dynamics, here we developed and characterized 16 polymorphic microsatellite markers. Variation evaluation showed the number of alleles ranged from two to 11 , and the observed and expected heterozygosity varied from 0.033 to 0.697 and from 0.033 to 0.867 , respectively. These markers will be useful for studying dispersal dynamics and associated population genetic structure during fast spread of $C$. savignyi.
\end{abstract}

Keywords Biological invasion - Ciona savignyi . Invasive species $\cdot$ Microsatellite $\cdot$ Solitary ascidian

Human-mediated introductions and spread of marine nonindigenous species at a global scale have sharply increased in the past decades, making coastal waters as one of the most invaded habitats (Carlton and Ruiz 2005). Among many problem-causing species, the Pacific transparent

P. Ni · Y. Lin · Y. Chen · Y. Zhao · A. Zhan $(\bowtie)$

Research Center for Eco-Environmental Sciences, Chinese Academy of Sciences, 18 Shuangqing Road, Haidian District, Beijing 100085, China

e-mail: zhanaibin@ hotmail.com

H. Li

South China Sea Environmental Monitoring Center, State Oceanic Administration, 155 Xingang Road West,

Guangzhou 510300, Guangdong, China ascidian Ciona savignyi is one of the most notorious invaders (Lambert and Lambert 1998). This invasive solitary ascidian, which is considered native to Japan and possibly northern Asia, has spread to temperate regions such as Pacific coast of North America, and even Southern Hemisphere such as New Zealand (Lambert and Lambert 1998; Smith et al. 2010). C. savignyi is very competitive in invaded habitats, resulting in profound changes to benthic communities by rapidly covering available substratum and excluding native species in a short period of time (Lambert and Lambert 1998).

Although negative effects caused by marine invaders have been well documented, studying their dispersal dynamics poses immense technical challenges, as available information pertaining to dispersal dynamics is often incomplete in aquatic habitats. The use of robust genetic analyses based on polymorphic markers can advance our understanding of both dispersal dynamics and associated population genetic patterns (e.g. Zhan et al. 2010). To investigate the dispersal dynamics, as well as population genetic structure in both native and invaded ranges for the highly invasive $C$. savignyi, here we developed and characterized 16 polymorphic microsatellite markers.

Microsatellite markers were developed based on the $C$. savignyi genome sequence (http://asia.ensembl.org/Ciona savignyi/Info/Index). The downloaded whole genome sequences were mined for microsatellites using the methods of Zhan et al. (2010). Unlinked microsatellites with sufficient flanking sequences were chosen for primer design using Primer Premier version 5 (Premier Biosoft International). Forward primers were $5^{\prime}$-end fluorescently labeled with one of the following four fluorescent dyes, 6-carboxyfluorescein (6-FAM), hexachlorofluorescein (HEX), carboxy-X-rhodamine (ROX), and carboxytetramethylrhodamine (TMR). 
Table 1 Characterization of 16 polymorphic microsatellites for the highly invasive ascidian, Ciona savignyi. $T_{a}=$ optimized annealing temperature; $N_{A}=$ number of alleles; $H_{O}=$ observed heterozygosity; $H_{E}=$ expected heterozygosity

\begin{tabular}{|c|c|c|c|c|c|c|c|c|}
\hline Locus & Repeat motif & Primer sequences & Dye used & Size (bp) & $T_{\mathrm{a}}$ & $N_{\mathrm{A}}$ & $H_{\mathrm{O}}$ & $H_{\mathrm{E}}$ \\
\hline CS3689 & $(\mathrm{GAT})_{5}$ & $\begin{array}{l}\text { F: CTGAATACAAGAGGCTAA } \\
\text { R: GACACAATCTTGCCATCT }\end{array}$ & ROX & $340-364$ & 56 & 6 & 0.219 & 0.259 \\
\hline CS5209 & $(\mathrm{ACCAC})_{3}$ & $\begin{array}{l}\text { F: GTGGATCAGTTTGGTTCCCT } \\
\text { R: ATACGACACTCTGTGCTTGTC }\end{array}$ & 6-FAM & $256-266$ & 50 & 2 & 0.033 & 0.033 \\
\hline CS6397 & $(\mathrm{TGA})_{5}$ & $\begin{array}{l}\text { F: TGGATAACCTCCGCTTGTTC } \\
\text { R:CATCTGGTTCTGGTGATGTAGTAG }\end{array}$ & TMR & $170-179$ & 56 & 4 & 0.609 & 0.727 \\
\hline CS7688 & $(\text { TATCC })_{3}$ & $\begin{array}{l}\text { F: TGAACCCAGCGGATTAATGG } \\
\text { R: GATCCAACGAGTGCTTGAGT }\end{array}$ & HEX & $254-274$ & 62 & 4 & 0.328 & 0.422 \\
\hline CS7928 & $(\mathrm{AAT})_{5}$ & $\begin{array}{l}\text { F: CAGTTCAGACCGGCTAATGA } \\
\text { R: CTGGGTAAGGTCATAGGTGAAG }\end{array}$ & 6-FAM & $280-283$ & 50 & 2 & 0.030 & 0.088 \\
\hline CS9784 & $(\mathrm{GAT})_{5}$ & $\begin{array}{l}\text { F: CCAAGACTAACCAGGCGATAC } \\
\text { R: TGACCCGATCATCCAAATCC }\end{array}$ & HEX & $153-156$ & 50 & 2 & 0.257 & 0.269 \\
\hline CS50352 & $(\mathrm{ACC})_{5}$ & $\begin{array}{l}\text { F: TGGTTTGTGGGTACTTGCTGG } \\
\text { R: TCATTGTCGCTGTTTTTATCT }\end{array}$ & ROX & $146-165$ & 56 & 5 & 0.400 & 0.485 \\
\hline CS50771 & $(\text { TATCC })_{3}$ & $\begin{array}{l}\text { F: CTATCCCCCTACCCTCTTA } \\
\text { R: CGTACCCGAGGGCACCA }\end{array}$ & 6-FAM & $151-156$ & 56 & 2 & 0.306 & 0.261 \\
\hline CS52718 & $(\mathrm{AAC})_{5}$ & $\begin{array}{l}\text { F: GAGGCGAATTGTCCCAT } \\
\text { R: TCCCTCCAACAATGCGG }\end{array}$ & TMR & $348-357$ & 62 & 3 & 0.400 & 0.540 \\
\hline CS56726 & $(\mathrm{CACCCC})_{3}$ & $\begin{array}{l}\text { F: CGATTGGGTTGACGCTTA } \\
\text { R: CTTGGGGGGTCGGGGTGC }\end{array}$ & ROX & $231-237$ & 62 & 2 & 0.111 & 0.170 \\
\hline CS60921 & $(\mathrm{TAAAC})_{5}$ & $\begin{array}{l}\text { F: CGTCTTATCACGCACAAC } \\
\text { R: CCGCAGCAGCATTATCAA }\end{array}$ & HEX & $236-241$ & 56 & 6 & 0.214 & $0.714^{\mathrm{b}}$ \\
\hline CS4940 & $(\mathrm{GAG})_{5}$ & $\begin{array}{l}\text { F: AAAGAAGTGCTCGCGAAGTC } \\
\text { R: AGTCCTCATCGCTCTCATTCT }\end{array}$ & HEX & $116-125$ & 61 & 3 & 0.111 & $0.667^{\mathrm{b}}$ \\
\hline CS8713 & $(\mathrm{CAA})_{5}$ & $\begin{array}{l}\text { F: TCCCAACAACTGCCAACT } \\
\text { R: GCTCGCATCTGTTGTTCTTG }\end{array}$ & ROX & $148-169$ & 50 & 5 & 0.697 & 0.658 \\
\hline CS61676 & $(\mathrm{AGG})_{5}$ & $\begin{array}{l}\text { F: CCTCCTGCCGCGCTACCTTCT } \\
\text { R: TCCTGGCCCCGACTCCATCTT }\end{array}$ & HEX & $142-185$ & 56 & 11 & 0.500 & 0.867 \\
\hline CS62319 & $(\mathrm{AAGAA})_{3}$ & $\begin{array}{l}\text { F: GAGATATCAGTGGGAAGG } \\
\text { R: GAATACGATCAGCTCCAG }\end{array}$ & TMR & $251-257$ & 56 & 3 & 0.034 & 0.100 \\
\hline CS63497 & $(\mathrm{TCA})_{5}$ & $\begin{array}{l}\text { F: GGTGGAGGTGGGGTTGTA } \\
\text { R: GCCTTGTCGCCGTAGTTG }\end{array}$ & ROX & $276-315$ & 61 & 7 & 0.514 & 0.657 \\
\hline
\end{tabular}

b illustrates significant deviation from Hardy-Weinberg equilibrium (HWE) after Bonferroni correction

We used a population $(N=36)$ collected from the Sanggou Bay $\left(37^{\circ} 09^{\prime} \mathrm{N}, 122^{\circ} 30^{\prime} \mathrm{E}\right)$, Shandong Province, China to characterize variation of these microsatellite markers. The tissue around siphons was used to extract total genomic DNA using the standard phenol/chloroform method. PCRs were performed in a reaction volume of $12.5 \mu \mathrm{L}$ containing $1 \mathrm{U}$ Taq DNA polymerase (Takara), $0.2 \mu \mathrm{M}$ primers, $2 \mu \mathrm{M} \mathrm{Mg}^{2+}, 100 \mu \mathrm{M}$ each dNTP, and $50 \mathrm{ng}$ genomic DNA. PCRs were programmed as: $95{ }^{\circ} \mathrm{C}$ for $5 \mathrm{~min}$, followed by 35 cycles of $95{ }^{\circ} \mathrm{C}$ for $30 \mathrm{~s}$, locusspecific annealing temperature (Table 1) for $30 \mathrm{~s}, 72{ }^{\circ} \mathrm{C}$ for $30 \mathrm{~s}$, and a final extension at $72{ }^{\circ} \mathrm{C}$ for $5 \mathrm{~min}$. Amplified fragments were separated on an ABI 3130XL automated sequencer with the GeneScan ${ }^{\mathrm{TM}}-500 \mathrm{LIZ}^{\mathrm{TM}}$ internal size standard and scored using GENEMAPPER ${ }^{\circledR}$ version 4.0 (Applied Biosystems). Diversity indices including the number of alleles $\left(N_{\mathrm{A}}\right)$, observed heterozygosity $\left(H_{\mathrm{O}}\right)$ and expected heterozygosity $\left(H_{\mathrm{E}}\right)$ were calculated using Genepop online version (http://wbiomed. curtin.edu.au/genepop/). Hardy-Weinberg equilibrium was tested using Genepop for all loci, and sequential Bonferroni correction was applied for multiple tests to avoid Type I errors. The possibility of occurrence of null allele(s) and large allele dropout was tested using Micro-Checker version 2.2.0 (van Oosterhout et al. 2004).

Of the 72 primer pairs examined, 16 produced PCR products that were clear enough to score and were polymorphic. Characterization of these microsatellite markers 
in the population showed a moderate level of polymorphism. The number of alleles varied from two to 11, and the observed heterozygosity and expected heterozygosity ranged from 0.033 to 0.697 and from 0.033 to 0.867 , respectively (Table 1). After sequential Bonferroni correction for multiple tests, only two loci (CS60921 and CS4940) were found to depart significantly from HardyWeinberg equilibrium and showed heterozygote deficiency (Table 1). A further test based on Micro-Checker showed the presence of null alleles at these two loci. The microsatellite markers developed here will be useful for investigating spread dynamics and population genetic structure during biological invasions of $C$. savignyi.

Acknowledgments This work was supported by the National Natural Science Foundation of China (31272665) and 100 Talents Program of the Chinese Academy of Sciences to A.Z., and by Comprehensive Evaluation Methods for Quality of Marine Environments in South China Sea [DOMEP(MEA)-01-03].

\section{References}

Carlton JT, Ruiz GM (2005) Vector science and integrated vector management in bioinvasion ecology: conceptual frameworks. In Mooney HA, Mack RN, McNeely JA, Neville LE, Johan Schei P, Waage JK (eds) Invasive alien species: a new synthesis, Covelo, Island Press, California, pp 36-58

Lambert CC, Lambert G (1998) Nonindigenous ascidians in southern California harbors and marinas. Mar Biol 130:675-688

Smith KF, Cahill PL, Fidler AE (2010) First record of the solitary ascidian Ciona savignyi Herdman, 1882 in the Southern Hemisphere. Aquat Invasions 5:363-368

van Oosterhout C, Hutchinson WF, Wills DPM, Shipley P (2004) MICRO-CHECKER: software for identifying and correcting genotyping errors in microsatellite data. Mol Ecol Notes 4:535-538

Zhan A, MacIsaac HJ, Cristescu ME (2010) Invasion genetics of the Ciona intestinalis species complex: from regional endemism to global homogeneity. Mol Ecol 19:4678-4694 